\title{
Reasons and decision-making processes for applying to nursing school among nurses showing delayed professional development
}

\author{
Chihiro Kawakami, Rintaro Imafuku, Koji Tsunekawa, Takuya Saiki \\ Medical Education Development Center, Gifu University, Gifu, Japan
}

Received: May 27, 2018

DOI: $10.5430 /$ jnep.v9n1p21
Accepted: August 22, 2018

Online Published: August 27, 2018

URL: https://doi.org/10.5430/jnep.v9n1p21

\begin{abstract}
Objectives: The characteristics of nurses who leave the profession after completing nursing school have not been examined sufficiently. Therefore, we examined the reasons for applying to nursing school and the process of arriving at the decision to apply among nurses showing delayed professional development.

Methods: Participants were eight junior nurses showing a delay in their growth as nurses, who were working at two teaching hospitals. We utilized semi-structured interviews, and the transcripts were quantitatively and qualitatively analyzed.

Results: A frequency analysis of the reasons identified in the transcripts revealed twelve primary reasons for applying to nursing school, such as attraction to the nursing profession, selection from among the different options in the medical field, scholastic aptitude for post-high-school entrance examinations, and academic interest. A qualitative analysis of the process by which participants decided to apply to nursing school yielded three themes: tendency to depend on others, superficial consideration of their own aptitude for the nursing profession, and obtaining a nursing license as a means of accomplishing another purpose. Conclusions: We revealed a number of reasons why newly qualified nurse exhibit delayed professional development as well as three characteristics of their decision-making to apply to a nursing school. The practical implications for the interview process in selection of applicants, effective usage of role model, and coaching are indicated for future nursing education.
\end{abstract}

Key Words: Nursing education, Delay in growth, Entrance examination

\section{INTRODUCTION}

As healthcare professionals, nurses are increasingly expected to be capable of handling complex problems in their patients and patients' family efficiently and effectively to meet diverse societal needs. Educators must focus on fostering nurses with resilience to deal with the complexity and uncertainty of patient care, which can help maintain and improve the quality of care. However, several studies have shown that the number of nurses who end up leaving the profession has increased because of a lack of enjoyment, poor relationships with other nurses, unsupportive work environments, and perceiving themselves as unsuitable for the profession. ${ }^{[1,2]}$ One major reason that nurses leave the profession, according to Flinkman, is a strong dissonance between the reality of nursing and what nurses had imagined it would be before entering the field. ${ }^{[3]}$

A potentially key phase for intervening in this dissonance, and thereby retaining competent nurses, is selection process used by the nursing school. Currently, nursing schools uti-

*Correspondence: Chihiro Kawakami; Email: uribou@gifu-u.ac.jp; Address: Medical Education Development Center, Gifu University, Gifu, Japan. 
lize several methods to screen admission applicants, such as academic achievement tests, essays, one-on-one interviews, or multiple miniature interviews. ${ }^{[4-6]}$ Interviews are a powerful, interactive way of determining whether applicants are a good fit for clinical practice, particularly when the discussion focuses on an applicant's motivation for becoming a nurse or reasons for applying to nursing school. Typical motivations to become a nurse are parental occupation or recommendation, good average registered nurse pay, anticipated dedication to patients, influence of media, interest in the human body and psychology, etc. Other reasons for becoming a nurse are somewhat more practical, such as residing in close proximity to a nursing school. ${ }^{[7-11]}$

Understanding the reasons and processes by which underperforming nurses decided to apply to nursing schools should be beneficial for teachers to predict the I think you mean to predict "the performance success of future nurses". In fact, previous studies on health profession education argue that the characteristics of the applicants and their job suitability are correlated. For instance, Papadakis et al. reported that problems with self-awareness, grades, and behavior at the earlier stages of education were indicators of future behavior among physicians facing disciplinary action for major incidents. ${ }^{[12,13]}$ To the best of our knowledge, the reasons and processes to apply to nursing schools of underperforming nurses have not been examined. Therefore, the aims of this study were to reveal (1) the reasons that underperforming nurses applied to nursing school and (2) the process by which they decided to apply to the school.

\section{MethodS}

\subsection{Participants}

We recruited participants with the cooperation of the Department of Nursing at two teaching hospitals with 600 or more beds. To be eligible for participation, nurses had to be qualified as nurses but show a delay in professional growth for the first three years. In most hospitals in Japan, the Department of Nursing utilizes a three-year training program following the employment of newly qualified nurses as a means for developing competent nurses. To determine whether a nurse is competent, both of the teaching hospitals employ the training guideline of the Japanese Nursing Association's (JNA) Clinical Ladder. ${ }^{[14]}$ In this study, we defined delayed professional growth as follows: the nurse does not meet the standards outlined in the JNA Clinical Ladder training guidelines within three years of employment, as judged by their instructors and nurse directors, resulting in their resignation or transfer to another division.
Nurses that met the inclusion criteria were identified and asked by the nursing department whether they were interested in participating. After obtaining the verbal informed consent, the Department of Nursing scheduled the interview with each participant. The author who conducted the interview was introduced to the participants on the day of the interview. At this time, the author explained the study objectives prior to obtaining participants' written consent so that author could make sure the participants' will to participate in this study again. Four participants from each of the two teaching hospitals participated, for a total of eight participants. Two participants were male. They are all participants of this study since it was not possible for us to obtain new participants after. This study was approved by the institutional review board of Gifu University (Number 25-385).

\subsection{Data gathering and analysis}

This qualitative study utilized semi-structured interviews to obtain data, each lasting for 20 minutes. Interviews were conducted in noise-free, private rooms to maintain patients' confidentiality. Each participant was asked why and how they decided to apply to the nursing school. All interviews were transcribed. Quantitative content analysis ${ }^{[15]}$ was conducted to analyze data on the reasons that participants applied to nursing school. We created categories of reasons based on previous papers. ${ }^{[7-11]}$ Frequency analysis was used to identify the main reasons for applying to nursing school. Thematic analysis of the interview data was used to analyze the particular process by which participants decided on whether to pursue nursing as a career. ${ }^{[16]}$ Two researchers (CK, TS) independently read the transcripts for several times to understand the text, found the keywords in the text, coded the data from the keywords and finally organized these codes into themes by discussing the initial theme repeatedly to modify and integrate the final theme. The validity of the analysis was verified by two other researchers (RI, KT) through the discussion of the final themes until we reached to the consensus.

\section{RESUlts}

\subsection{Reasons for applying to nursing school}

Table 1 shows descriptive data regarding the specific reasons for applying to nursing school. The reasons are listed according to their frequency of mention in the interview transcriptions. The most common reasons were as follows: attraction to the nursing profession; selection from among different options in the medical field; scholastic aptitude at the time of post-high-school entrance examinations; and academic interest. 
Table 1. Reasons for applying for nursing studies

\begin{tabular}{|c|c|c|c|c|c|c|c|c|c|}
\hline \multirow{2}{*}{ The reason for applying } & \multicolumn{8}{|c|}{ Identification of the participants } & \multirow{2}{*}{ Total } \\
\hline & A & $\mathbf{B}$ & C & D & $\mathbf{E}$ & $\mathbf{F}$ & G & $\mathbf{H}$ & \\
\hline $\begin{array}{l}\text { 1) Attraction to the nursing profession } \\
\text { "After all, [being a] nurse is a wonderful job” }\end{array}$ & & & & + & + & + & + & + & 5 \\
\hline $\begin{array}{l}\text { 2) Selection from among different options in the medical field } \\
\text { "At first, I thought that I just wanted to be one of the medical staff, but finally I } \\
\text { decided that a nurse would be nice.” }\end{array}$ & & + & & + & + & + & + & & 5 \\
\hline $\begin{array}{l}\text { 3) Level of academic competency } \\
\text { "Rather than studying hard at high school, I am aiming to become a nurse since it } \\
\text { seemed easy for me..." }\end{array}$ & & + & & + & + & + & & & 4 \\
\hline $\begin{array}{l}\text { 4) Academic interest } \\
\text { "I was interested in the human body as well" }\end{array}$ & & & & & + & + & & + & 3 \\
\hline $\begin{array}{l}\text { 5) Income and secure employment } \\
\text { "I hear that I can get a good salary" }\end{array}$ & + & & + & & & + & & & 3 \\
\hline $\begin{array}{l}\text { 6) Parents' recommendation } \\
\text { "Since I was small, my mother told me that I should have a marketable skill” }\end{array}$ & + & & & + & & & & & 2 \\
\hline $\begin{array}{l}\text { 7) Influence of parents who are medical staff } \\
\text { "My mother was a nurse and I grew up listening to stories about her job.” }\end{array}$ & & & & + & & + & & & 2 \\
\hline $\begin{array}{l}\text { 8) Hope to be useful to others and society } \\
\text { "The nurse is closest to the patient" }\end{array}$ & & & & + & & & + & & 2 \\
\hline $\begin{array}{l}\text { 9) Being qualified } \\
\text { "I was told that it would be better if I had a license, so I decided to become a nurse.” }\end{array}$ & + & & & + & & & & & 2 \\
\hline 10) Family's experience of hospitalization & & & & & & & & & \\
\hline $\begin{array}{l}\text { "My mother was once hospitalized. I was impressed with [nurses'] interaction with } \\
\text { patients." }\end{array}$ & & & & & & & & + & 1 \\
\hline $\begin{array}{l}\text { 11) Recommendations from persons other than relatives (e.g., teachers) } \\
\text { "My teacher said that you could not make a living from art." }\end{array}$ & + & & & & & & & & 1 \\
\hline $\begin{array}{l}\text { 12) Geographical reasons } \\
\text { "I can get to the nursing school from my house easily" }\end{array}$ & & & & + & & & & & 1 \\
\hline
\end{tabular}

\subsection{Process of deciding to apply to nursing school Theme 1: Tendency to depend on others}

Some participants did not have a strong intrinsic desire to apply to nursing school and did not actively pursue this option. For such participants, it was the encouragement of those around them-such as their parents and teachers-that led to their decision to apply. Others wanted to purse another field, but were dissuaded by others around them, who told them that their desired field would not be a realistic option. This feedback led individuals to conclude that what they wanted to do was a poor career choice, which made them unable to follow through with it. Finally, there were some participants who did originally want to become a nurse. In making their decision, they sought out the advice of those around them (e.g., family and teachers) to determine if their pursuit of a nursing career was appropriate.

"From the beginning, I never wanted to become a nurse and really wanted to study art. [But] I was told that I could not make a living from art. When my family, teachers, and those around gave me this feedback, I began to think that choosing art as a career was a mistake and that I should not be following my dream.” (A)

"Although I wavered in making a decision, I finally made up my mind to become a nurse after discussing with those around me." (F)

\section{Theme 2: Superficial consideration of their own aptitude for the nursing profession}

This theme represented a focused, desire-oriented approach to selecting a career. In short, for over half the participants, the positive aspects of interacting with people as a nurse or their own longing to be a nurse contributed to their decision to choose nursing. However, when reflecting on their decision-making process, these nurses realized that they had engaged in little introspective thinking on whether they had the attributes or aptitude to be a nurse.

"My mother was once hospitalized. I noticed the interaction between patient and nurse. I decided 
to become a nurse as the profession involves directly interacting with the patient." $(\mathrm{H})$

"As expected, nursing is a profession at the frontline of interacting with the patient. [But] to be honest, I never thought about whether I was suited to be a nurse." $(\mathrm{G})$

"Ever since I was young, my mother [who was a nurse] told me that I should have a marketable skill." (D)

Theme 3: Obtain a nursing license as a means of accomplishing another purpose

Some participants wanted to obtain a nursing license in order to accomplish another purpose. First, some participants attended a nursing school in order to obtain a nurse's license. These participants had ambitions beyond working as a clinical nurse in Japan, such as working abroad or becoming a researcher. In other words, these participants had set their sights on what they wanted to do in the future and identified nursing as a beginning step in reaching their goals. Second, some participants merely sought qualifications that would allow them to find a secure and stable line of work. They had no strong passion to work in the nursing field, instead choosing it passively by process of elimination. More specifically, in exploring options for secure employment, they had a vague notion of working in a medical field, and of the various medical professions, they chose nursing because they perceived it to be less difficult to obtain a license.

"I was thinking there was something I could do overseas. After studying English related to the nursing field, I thought there would be volunteer opportunities." (B)

"When I was in high school, I wanted to become a biology researcher... After 2 years of failing to get into another university, it occurred to me that there was a option of getting into the medical field as a nurse." (E)

"It is easier to find a nursing position [in a hospital]. I heard that even physical therapists have a very hard time finding employment." (F)

"As possessing a license ensures a stable life, I felt that the pathway to becoming a nurse was easiest." (A)

\section{Discussion}

To the best of our knowledge, this study is one of the few to have investigated nurses' reason for deciding to apply to nursing schools and their pathways to deciding to enter the nursing profession among nurses showing delayed professional development.

\subsection{Reason for applying to a nursing school}

We identified numerous reasons that this group of nurses chose to enter nursing school. Our results align with previous studies on why applicants chose to enter nursing school: specifically, the majority of applicants gave positive, forwardthinking reasons such as nursing is an occupation with growth potential or a job that can lead to a life-long career. ${ }^{[7-11]}$ On the other hand, a minority of applicants chose to enter nursing at the recommendation of parents and teachers, the salary, and location. ${ }^{[7-11]}$ Interestingly, the reasons given in our study did not differ substantially from the reasons given by high school students seeking post-high-school education. ${ }^{[17]}$ In other words, this finding suggests that it is difficult to predict which individuals will show delayed development as a nurse after working for three years based on their reasons for applying to nursing school. Thus, interviewers must bear in mind that asking applicants their reason for applying to nursing school is not going to identify applicants at risk of delayed development in undergraduate education.

\subsection{The process how they decide to apply to nursing school}

Three themes were extracted from the underlying reasons for deciding to apply nursing school: (1) tendency to depend on others; (2) superficial consideration to their own aptitude for the nursing profession; and (3) obtain a nursing license as a means of accomplishing another purpose.

The results may suggest that a passive attitude appears to be a consistent factor among nurses showing slow professional development. When participants' decision-making is dependent on others, the decision-making pathway is considered passive. In this study, most of the participants had a passive interest in the nursing profession at the time of applying for nursing school. A passive attitude or lack of strong motivation towards nurse can influence their studying or negatively influence their satisfaction with the student's school experience. ${ }^{[18]}$

By contrast, our findings also indicate the immaturity in the ability to be introspective among the participants of this study who demonstrated the delayed professional development in the nursing profession. We should embrace the results of Theme 2 demonstrating that they have a strong desire or fascination in the field since those are regarded as positive indicators of proactive decision-making, although we must remember that it may reflect a lack of in-depth thinking about whether one is suited to the nursing profession. 
We identified two different motivational factors among applicants who were seeking to obtain a nursing license. Some students were interested in working outside of the clinical field, such as a researcher or international volunteer. Price ${ }^{[19]}$ noted that there are many career options in today's environment, and that pursuing nursing work in a hospital setting is a stereotype. For these applicants, a nursing license is useful for achieving their ultimate career goal. However, such individuals might not encounter a role model whose career orientation is similar to theirs. This could lead to a loss of motivation and delayed professional growth, as having role models is regarded as a crucial factor for success in the nursing career. ${ }^{[20,21]}$ Some applicants to nursing school are looking for a secure position to make a living. For these applicants, their motivation to pursue a career in nursing is extrinsic, rather than intrinsic. Extrinsic motivation is inherently not sustainable, and it might be difficult for extrinsically motivated individuals to derive satisfaction during studying or in the performance. In fact, when an individual is driven by extrinsic motivation, they may become detached from theirfield, which can lead to sloppy performance. ${ }^{[22]}$ They might also face a gap between the technical skills and abilities required for clinical nursing and their own current skills/abilities. This can lead to cognitive dissonance, ${ }^{[23]}$ for which relief is attained only by leaving the nursing field.

\subsection{Implications}

This study has some practical implications, ranging from the entrance examination process to supporting students who have been admitted to nursing school. In entrance examinations, it might be necessary to carefully inquire about not only applicants' reason for applying to a nursing school but also their decision making processes for application. Furthermore, whether the nursing profession is the applicant's first choice of a career or not is an important factor in determining whether the applicant will remain in the nursing field in the long term. ${ }^{[21]}$ We further suggest that applicants be required to complete a self-assessment of their own suitability for the nursing profession and to explain their reasoning.

Coaching newly qualified nurses is also important. For instance, coaching system should strive to create a career support environment that increases new nurses' intrinsic moti- vation. Such an environment can be cultivated via coaching based on an understanding of the individual's goals from a broad perspective. The approach might help nurses working in hospitals avoid an identity crisis in determining what they really want to do as a career, and may lead them in a positive direction. In addition, creating opportunities for applicants to meet a variety of role models could help in their career development in the nursing field. ${ }^{[20,21]}$ Furthermore, organizing opportunities for applicants to engage in introspection about the nursing perspective and supporting them in realizing their intrinsic motivation might help applicants adjust to their working environment.

\subsection{Limitations}

There are several limitations in this study. First, only two teaching hospitals were involved in the study, and the field of this study was limited to only hospital settings, which limits the generalizability of the findings. In addition, only ten underperforming newly qualified nurses agreed to participate in the study. Second, our findings might reflect characteristics unique to Japanese nurses; therefore, the validity of the results should be confirmed outside of Japan. Finally, our focus was on nurses' reasons for wanting to enter nursing school, and therefore cannot fully account for all reasons for nurses' delayed professional development. We also have to note the possibility that nurses who demonstrated adequate professional development might have had a similar type of motivation and patterns of decision making in choosing to enter nursing school. Therefore, in depth exploration of students' learning experiences prior to graduation as well as during their training period are needed. This would help us qualitatively understand, in more depth, nurses judged as showing a delay in professional growth.

\section{Conclusion}

This study the revealed nurses' reasons for deciding to apply to nursing school and several characteristics of the decisionmaking process in selecting nursing as a career among nurses that showed delayed professional development.

\section{Conflicts of Interest Disclosure}

The authors declare no conflict of interests.

\section{REFERENCES}

[1] Uchino K, Shimada R. Literature review on the leaving of newly nurse in Japan. The Japan Society of Health Sciences of Mind and Body. 2015; 11(1): 18-23.

[2] Hayes LJ, O’Brien-Pallas L, Duffield C, et al. Nurse turnover: a literature review. International Journal of Nursing Studies. 2006; 43(2): 237-263. PMid:15878771 https ://doi.org/10.1016/j. ijnurstu.2005.02.007

[3] Flinkman M, Isopahkala-Bouret U, Salanterä S. Young registered nurses' intention to leave the profession and professional turnover in 
early career: a qualitative case study. ISRN Nursing. 2013; 1-12.

[4] Salvatori P. Reliability and validity of admissions tools used to select students for the health professions. Advances in Health Sciences Education. 2001; 6(2): 159-175. https://doi.org/10.1023/A : 1011489618208

[5] Callwood A, Allan H, Courtenay M. Are current strategies for preregistration student nurse and student midwife selection 'fit for purpose' from a UK perspective? Introducing the multiple mini interview. Nurse Educaction Today. 2012; 32(8): 835-837. PMid:22705058 https://doi.org/10.1016/j.nedt.2012.05.019

[6] Rhodes CA, Nyawata ID. Service user and career involvement in student nurse selection: key stakeholder perspectives. Nurse Education Today. 2011; 31(5): 439-443. PMid:21036432 https : //doi.org/10.1016/j.nedt.2010.10.005

[7] Ichiyanagi Y, Taniyama M, Yamazaki C, et al. Development and validation of a scale to measure motivating factors for a student in choosing nursing as a career. Bulletin of Kawasaki City College of Nursing. 2009; 14(1): 21-27.

[8] Wilkes L, Cowin L, Johnson M, et al. The reasons students choose to undertake a nursing degree. Collegian. 2015; 22(3): 259-265. https://doi.org/10.1016/j.colegn.2014.01.003

[9] Jirwe M, Rudman A. Why choose a career in nursing? Journal of Advanced Nursing. 2012; 68(7): 1615-1623. PMid:22435896 https://doi.org/10.1111/j.1365-2648.2012.05991.x

[10] Mooney M, Glacken M, O’Brien F. Choosing nursing as a career: A qualitative study. Nurse Education Today. 2008; 28(3): 385-392. PMid:17888547 https ://doi.org/10.1016/j.nedt.2007.07 .006

[11] Law W, Arthur D. What factors influence Hong Kong school students in their choice of a career in nursing? International Journal of Nursing Studies. 2003; 40(1): 23-32. https : //doi .org/10.1016/S0 020-7489 (02) 00029-9

[12] Papadakis MA, Hadson CS, Teherani A, et al. Unprofessional behavior in medical school is associated with subsequent disciplinary action by a state medical board. Academic Medicine. 2004; 79(3): 244-249. https://doi.org/10.1097/00001888-200403000-00011

[13] Papadakis MA, Loeser H, Healy K. Early detection and evaluation of professionalism deficiencies in medical students: one school's approach. Academic Medicine. 2001; 76(11): 1100-1106. https: //doi.org/10.1097/00001888-200111000-00010

[14] Japanese Nursing Association. 2017. Available from: https : //ww w. nurse.or.jp/nursing/jissen/index.html

[15] Macduff C, Stephen A, Taylor R. Decision precision or holistic heuristic?: Insights on on-site selection of student nurses and midwives. Nurse Education in Practice. 2016; 16(1): 40-46. PMid:26213147 https://doi.org/10.1016/j.nepr.2015.06.008

[16] Braun V, Clarke V. Using thematic analysis in psychology. Qualitative Research in Psychology. 2006; 3(2): 77-101. https://doi .or g/10.1191/1478088706qp063oa

[17] Matsushita Y, Shibata K. Factors in early retirement of nurses newly graduated from college: motives of the selection of occupation and related factors half a year after employment. Bulletin of Yamanashi Prefectural University. 2004; 6: 65-72.

[18] Nakamura M, Azami R. Fundamental study on motivation to enroll as a factor influencing college adaptation. Bulletin of Edogawa University. 2017; 27: 301-308.

[19] Price SL Hall LM, Angus JE, Peter E. Choosing nursing as a career: a narrative analysis of millennial nurses' career choice of virtue. Nursing Inquiry. 2013; 20(4): 305-316. PMid:23551958 https://doi.org/10.1111/nin.12027

[20] Price SL. Becoming a nurse: a meta-study of early professional socialization and career choice in nursing. Journal of Advanced Nursing. 2009; 65(1): 11-19. PMid:19120580 https://doi .org/10.1 $111 / j .1365-2648.2008 .04839 . x$

[21] Salamonson Y, Everett B, Cooper M, et al. Nursing as first choice predicts nursing program completion. Nurse Education Today. 2014; 34(1): 127-131. PMid:23142172 https://doi.org/10.1016/j . nedt. 2012.10.009

[22] Ericsson KA, Krampe RT, Tesch-Römer C. The role of deliberate practice in the acquisition of expert performance. Psychological Review. 1993; 100(3): 363. https://doi.org/10.1037/0033-295 X.100.3.363

[23] Festinger L. A theory of cognitive dissonance. Redwood City, CA: Stanford University Press; 1962. 